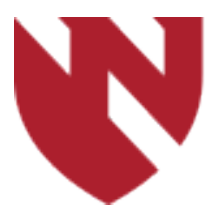

September 2020

\title{
The Clinical Relevance of Cement Volume in Percutaneous Vertebral Augmentation
}

\author{
Ravi G. Mirpuri \\ University of Nebraska Medical Center \\ Madhuri Are \\ University of Nebraska Medical Center \\ Virginia Hardie \\ University of Nebraska Medical Center \\ Michael J. Warden \\ University of Nebraska Medical Center \\ Robin High \\ University of Nebraska Medical Center
}

Tell us how you used this information in this short survey.

Follow this and additional works at: https://digitalcommons.unmc.edu/gmerj

Part of the Anesthesia and Analgesia Commons, Anesthesiology Commons, Higher Education

Commons, Surgical Procedures, Operative Commons, and the Therapeutics Commons

\section{Recommended Citation}

Mirpuri, R. G., Are, M., Hardie, V., Warden, M. J., , High, R. The Clinical Relevance of Cement Volume in Percutaneous Vertebral Augmentation. Graduate Medical Education Research Journal. 2020 Sep 29; 2(1). https://digitalcommons.unmc.edu/gmerj/vol2/iss1/9 


\title{
The Clinical Relevance of Cement Volume in Percutaneous Vertebral Augmentation
}

\author{
Abstract \\ Introduction: Vertebroplasty and Kyphoplasty are two forms of percutaneous vertebral augmentation \\ (PVA), in which polymethylmethacrylate cement is used to stabilize vertebral compression fractures \\ (VCF). This study sought to evaluate the relationship between cement volume and clinical outcomes, \\ including pain reduction, opioid use, and complication rate. \\ Methods: Retrospective chart review produced 88 patients who received PVA at a tertiary care outpatient \\ pain clinic. Cement volume, type of PVA, gender, level (thoracic vs lumbar) were collected, as well as \\ clinical outcomes of numeric pain score (NPS) reduction, opioid percent change (OPC), and \\ complications. Both pre-procedure and post-procedure (between 2-4 weeks) data were collected. \\ Results: Sixty-four patients (72.7\%) had statistically significant NPS reduction of $\geq 50 \%$ pain ( $p$ \\ Conclusion: Cement volume does not correlate with clinical outcomes of NPS reduction or OPC. \\ Furthermore, our study reinforced PVA as a beneficial treatment for reducing pain and opioid \\ consumption in patients with painful VCF.

\section{Keywords} \\ Kyphoplasty, Vertebroplasty, Back Pain/therapy, Pain Management, Treatment Outcome, Chronic Pain, \\ Cementoplasty, Fractures Compression

\section{Creative Commons License}

\section{(c) (i) $\ominus$} \\ This work is licensed under a Creative Commons Attribution-Noncommercial-No Derivative Works 4.0 \\ License.
}




\section{The Clinical Relevance of Cement Volume in Percutaneous Vertebral Augmentation}

Ravi G. Mirpuri', Michael J. Warden'1, Virginia Hardie', Robin High², Madhuri Are ${ }^{1}$

${ }^{1}$ College of Medicine, Department of Anesthesiology, Division of Pain Medicine, University of Nebraska Medical Center, Omaha, NE

${ }^{2}$ College of Public Health, Department of Biostatistics, University of Nebraska Medical Center, Omaha, NE

\begin{abstract}
Introduction: Vertebroplasty and Kyphoplasty are two forms of percutaneous vertebral augmentation (PVA), in which polymethylmethacrylate cement is used to stabilize vertebral compression fractures (VCF). This study sought to evaluate the relationship between cement volume and clinical outcomes, including pain reduction, opioid use, and complication rate.
\end{abstract}

Methods: Retrospective chart review produced 88 patients who received PVA at a tertiary care outpatient pain clinic. Cement volume, type of PVA, gender, level (thoracic vs lumbar) were collected, as well as clinical outcomes of numeric pain score (NPS) reduction, opioid percent change (OPC), and complications. Both pre-procedure and postprocedure (between two to four weeks) data were collected.

Results: Sixty-four patients $(72.7 \%)$ had statistically significant NPS reduction of $\geq 50 \%$ pain ( $\mathrm{p}$

Conclusion: Cement volume does not correlate with clinical outcomes of NPS reduction or OPC. Furthermore, our study reinforced PVA as a beneficial treatment for reducing pain and opioid consumption in patients with painful VCF.

\section{Introduction}

Background: Vertebroplasty and kyphoplasty are two forms of percutaneous vertebral augmentation (PVA) used to treat symptomatic or painful vertebral compression fractures (VCF). ${ }^{1,2} \mathrm{VCF}$ are associated with an estimated average hospital stay of 10 days and increased mortality if untreated. ${ }^{3,4}$ An estimated cost of $\$ 1.14$ billion dollars was spent in VCF treatment alone in 2005. 5 Symptomatic VCF can be associated with pain, chronic opioid consumption, and reduced quality of life. ${ }^{6,7}$

Cement volume is a commonly discussed topic in PVA. Increased cement volume has been suggested to be biomechanically advantageous for improving individual vertebral body stiffness, height, and loadsharing among the vertebral bodies., , $8-11^{-}$ However large fill volumes could incidentally promote biomechanical instability due to asymmetric distributions. ${ }^{12}$ Also adjacent vertebral fractures may be associated with increased cement volume possibly due to the increased stiffness of the repaired level. ${ }^{13}$ Besides biomechanics, dose-dependent increases in cement volume have been correlated with increased extravasation into the epidural space, neural foramen, intervertebral disc space, and vasculature that could lead to pulmonary embolism. ${ }^{11,14-15}$

Rational/Significance: Sometimes to avoid adverse events, clinicians minimize cement volume. A few studies suggest that increased cement volume does not correlate with improved clinical outcomes. ${ }^{16-18}$ However, another study suggests that clinical improvement does correlate with higher volumes, although the rate of complications was higher. ${ }^{19}$ Additionally, it is important to mention that some clincians question the benefit of PVA. Two seminal randomized controlled trials (RCT) using vertebroplasty showed no benefit in comparison to conservative treatment. ${ }^{20,21}$ However multiple studies of PVA and a recent kyphoplasty RCT did demonstrate improved outcomes of PVA when compared to conservative treatment. ${ }^{1,22-23}$ As such, there is a need for further studies to determine if low cement volumes would produce the same clinical benefit as high volumes.

Objective: The primary aim of this study is to evaluate the relationship between cement volume and clinical outcomes, including pain reduction, opioid use, and complication rate. Secondarily, this study sought to provide further evidence of PVA as a beneficial treatment for painful VCF.

\section{Methods}

A retrospective chart review was performed of all the patients that underwent kyphoplasty or vertebroplasty by a single experienced pain management physician at a tertiary care center between January 2009 and December 2016. The Institutional Review Board (IRB) approved this study, and waived the requirement for written informed consent. This manuscript was written to adhere to applicable Equator guidelines. Inclusion criteria consisted of accurate documentation of numeric pain scores (NPS), exact dosage of narcotic pain medication being consumed, surgical complications listed, and cement volume utilized during procedure. All patients who met the inclusion criteria were included in the study.

Patient Population: Percutaneous vertebral augmentation (PVA) was used to treat compression fractures in patients with axial back pain and either an underlying oncologic malignancy or osteoporosis. PVA would likely not be performed on compression fractures with symptoms exceeding one year unless MRI showed acute/subacute findings. Patients with the following imaging findings were excluded: $80 \%$ or greater vertebral height loss, burst fracture, disc retropulsion greater than $30 \%$, or significant clinical neurologic compromise secondary to compression

Approach: With the patient under general anesthesia in the operating room, local anesthetic was infiltrated from the skin to the pedicle of each target. Employing biplanar fluoroscopy throughout, she advanced the needles using a bipedicular approach in all cases. Once a tract was formed into the vertebral body, she injected cement material made of polymethylmethacrylate for vertebroplasty. In the case of kyphoplasty, inflatable balloons were used to create a cavity before injecting the cement. The injection was terminated if leakage was noted in the venous distribution, or beyond the vertebral endplates.

Outcome Measurements: Multiple outcome measures were collected in both the preprocedure and post-procedure settings. For the purpose of this study, pre-procedure was defined as the last data set collected prior to the procedure (typically between two weeks to one day before procedure). Post-procedure was defined as the data collected at the first outpatient visit following the procedure (typically between two to four weeks after procedure).

The following data were collected: numeric pain scores rated on a scale from 0 (no pain) to a 10 (worst imaginable pain), opioid dosage in morphine milliequivalents, and any complications during the procedure, ranging from any form of extravasation, infection, wound complications, or mortality. In addition, data relating to gender, cement 
volume, level (thoracic versus lumbar), and number of levels augmented were collected. Cement volumes recorded reflected the total amount used in a bipedicular approach. The purpose of the study was not to compare kyphoplasty versus vertebroplasty and the data were not analyzed separately unless specified in the results.

Opioid dosages were used to calculate opioid percent change (OPC). OPC was calculated by dividing the difference of pre-procedure and post-procedure opioid dose by the pre-procedure dose and multiplying by 100 to give a percent. In patients with multiple opioid medications, doses were converted to oral morphine milliequivalents prior to the calculation. This study did not account for non-opioid analgesic changes.

If a patient had multiple levels augmented in a procedure, outcomes of NPS and OPC were the same since they reflect the cumulative result of the entire procedure. Instead of analyzing the data by individual level, cement volume was averaged across all levels in our analysis to produce a single data point. This approach was selected to prevent overpowering and skewing of statistics by those with multilevel PVA.

Statistical Analysis: All t-tests performed were two-tailed with pairing based on the data being studied. T-tests were performed to compare if the mean change of NPS and OPC were significant. Additionally, t-tests were utilized to determine if NPS change or OPC were different across type of vertebral level. If data were categorical in comparison, such as gender vs $\geq 50 \%$ or $<50 \%$ improvement, a chi-square test was performed.

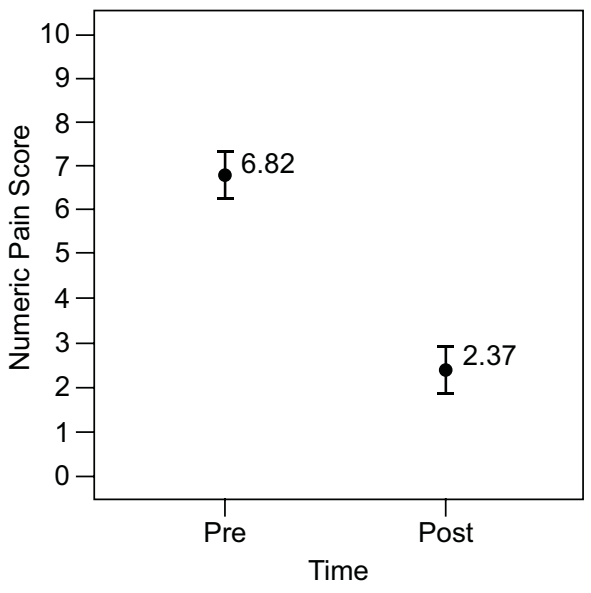

Figure 1. Average pain improvement. The mean Numeric Pain Score (NPS) pre-procedure (6.82) and post-procedure (2.37) with $95 \%$ confidence intervals displayed for a total of 88 patients. A mean reduction of 4.45 was present which was statistically significant $(p<.0001)$.
Linear regression adjusting for pre-NPS was performed to determine the relationship of either OPC or NPS change with cement volume. Logistic regression was used to analyze cement volume's influence on NPS when reported categorically $(\geq 50 \%$ and $<50 \%$ improvement). A professional statistician assisted with all the statistical analysis.

\section{Results}

Demographics: Eighty-eight patients were included in the study with females accounting for $53 \%$ of the patients. When analyzing the different types of PVA, 78 patients received kyphoplasty and 10 patients received vertebroplasty. For the entire cohort of 88 patients, 47 had PVA at multiple vertebral levels during the same procedure, with the following breakdown: 30 at two levels, 15 at three levels, 2 at four levels. The location of PVA during each procedure was as follows: 32 lumbar only, 28 thoracic only, and 28 who received both thoracic and lumbar PVA in the same procedure. Cement volume used per vertebral level ranged from 1 to $8 \mathrm{~mL}$ with 55 patients receiving an average of $\leq 3 \mathrm{~mL}$ and 33 patients receiving $>3 \mathrm{~mL}$.

Change in Numeric Pain Score (NPS): For the entire cohort of 88 patients, we noted a statistically significant reduction in the mean NPS by $4.45 \%(\mathrm{p}<0.0001)$ from a preprocedure value of 6.92 to a post-procedure value of 2.37. (Figure 1). This outcome persisted even when comparing patients with $\geq 50 \%$ NPS ( $n=64$ ) with those patients with $<50 \%$ reduction $(\mathrm{N}=24, \mathrm{p}<.001)$. In contrast, we found no statistically significant difference $(p=0.26)$ for decrease in the NPS between lumbar (mean reduction of 4.16) versus thoracic (mean reduction of 5.06) levels of PVA. Similarly, gender had no influence with an equivalent percentage of females $(72.34 \%)$ and males (73.17\%) demonstrating $\geq 50 \%$ reduction in NPS $(\mathrm{p}=0.93)$.

Linear regression using pre-NPS as the covariate showed that cement volume did not have a significant effect on the change in NPS ( $\mathrm{p}=0.173$ ) as demonstrated in Figure 2. When analyzed as a categorical variable, there was no statistical difference in NPS reduction between patients who received cement volumes of $\leq 3 \mathrm{ml}$ (mean reduction of 4.16) versus those who received $>3 \mathrm{ml}$ (mean reduction of $4.94, \mathrm{p}=0.25$ ).

Opioid Reduction: Seventy-two patients who were on opioids pre-procedure were included in this analysis. We noted a mean OPC reduction of $48 \%$. A statistically significant difference $(\mathrm{p}<0.0001)$ was noted between patients with opioid reduction $(n=63)$ when compared to patients $(n=9)$ with no improvement in opioid consumption. (Figure $3)$. There was no difference $(\mathrm{p}=0.71)$ in opioid reduction between lumbar $(\mathrm{n}=25$, mean reduction $=44 \%)$ versus thoracic $(n=22$, mean reduction $=49 \%$ ) levels of $\mathrm{PVA}$.

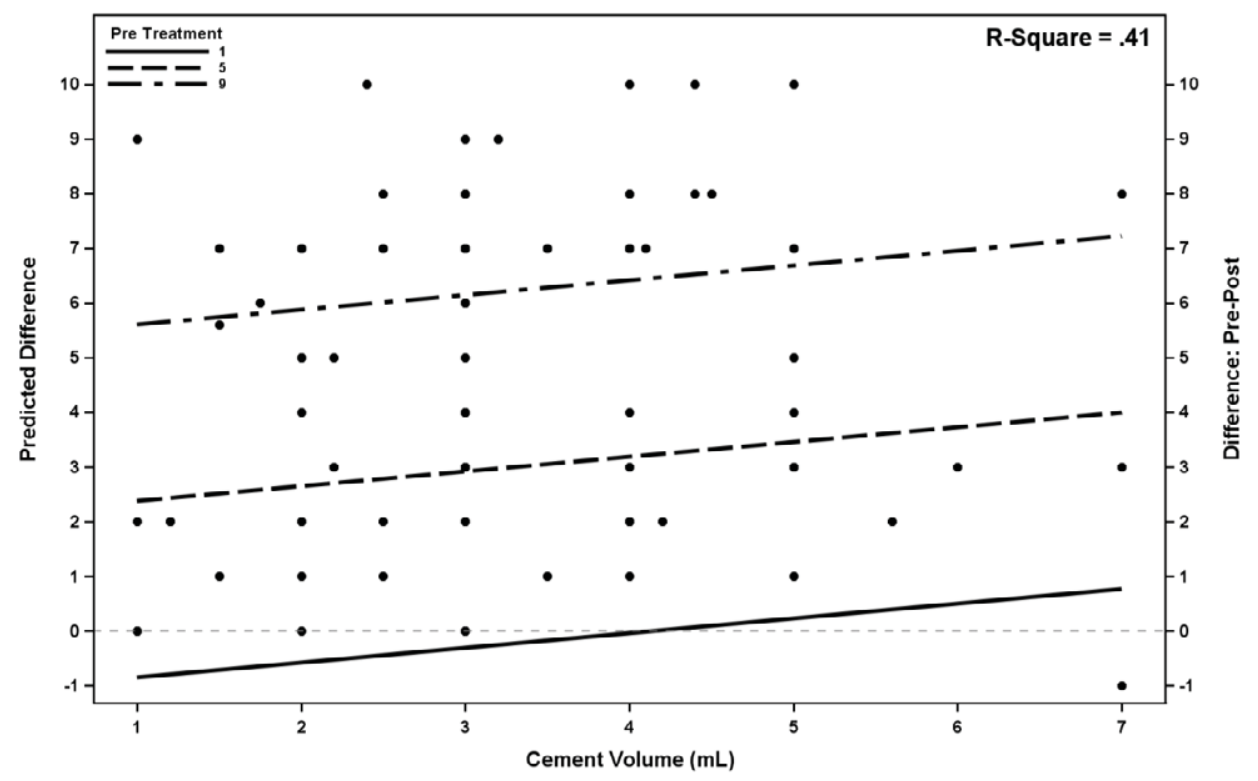

Figure 2. Difference in pain by cement volume and pre-treatment score. Scatter plot with linear regression analysis using pre NPS as the covariate shows the effect of cement volume on NPS change. Three regression lines are drawn with various pre-treatment NPS scores $(1,5,9)$ that failed to show statistical significance $(p=0.173 ; R 2=0.41)$. Although the vertical axes are the same for the difference scores, conceptually the left axis refers to the regression lines and the right vertical refers to the points plotted in the interior. Abbreviations: NPS=Numeric Pain Score 
We then analyzed if there was an effect of cement volume on opioid dosage reduction. Linear regression with two independent variables (adjusted for pre-NPS covariate and relationship of opioid decrease with cement volume) showed no relationship of opioid decrease with cement volume $(p=.299)$ (Figure 4).

\section{Complications/Adverse Reactions: A} total of nine complications (four intradiscal extravasations, three pulmonary vessel cement uptakes, and two other uncomplicated extravasations) were reported for a total complication rate of $10.2 \%$. However, it should be noted that all complications were asymptomatic with the exception of one patient treated for symptomatic dyspnea after pulmonary vessel cement uptake. The other complications were noted incidentally on follow up imaging or during fluoroscopy. None of the patients were noted to experience more than one complication. A complete breakdown of complications by cement volume $(\leq 3 \mathrm{ml} v \mathrm{vs}>3 \mathrm{ml})$ and type of procedure (kyphoplasty vs vertebroplasty) can be found in Table 1 .

\section{Discussion}

Our retrospective study of 88 patients who received PVA demonstrated multiple findings. Patients experienced statistically significant NPS improvement, with $72.7 \%$ of them

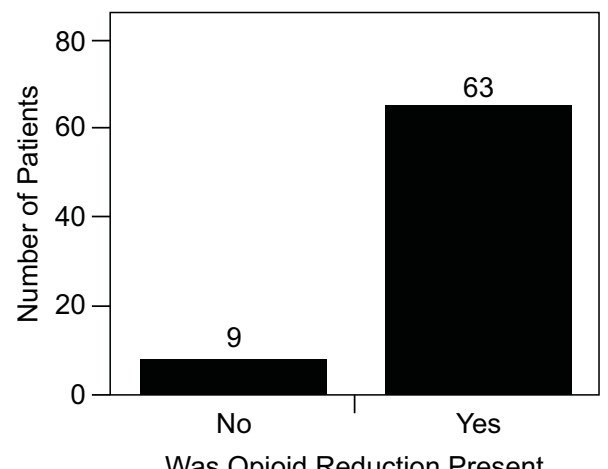

Figure 3. Reduction in opioids after treatment. Graphical display of patients who demonstrated any opioid reduction versus those with no improvement in opioid consumption in a categorical fashion. Seventy-two patients who were on opioids pre-procedure were included in this analysis. We noted a mean opioid percent change of $48 \%$. Following treatment with percutaneous vertebral augmentation, a statistically significant number of patients experienced opioid reduction $(n=63)$ when compared to patients $(n=9)$ with no reduction in opioid consumption $(p<0.0001)$. achieving $\geq 50 \%$ pain reduction at the first follow up appointment. Importantly, previous opioid consumers were able to decrease their opioid consumption by $48 \%$, which was statistically significant. Our results are in congruity with the findings of other similar studies. ${ }^{22,24}$ Our analysis also showed that neither gender nor vertebral level (thoracic vs. lumbar) had any influence on our measured outcomes.

Our study also demonstrated that cement volume did not have any statistically significant effect on NPS or opioid reduction, which is similar to findings from previous studies. ${ }^{16,17}$ Although not statistically significant, the $\mathrm{R}^{2}$ in both regression graphs (Figures $2 \& 4$ ) showed a positive correlation between cement volume and both NPS and opioid reduction. It is likely that a study with a larger sample size could potentially demonstrate a beneficial effect of cement volume.

We noted a cement leakage rate of $10.2 \%$ which is much lower than the findings reported by Zhan et al. ${ }^{14}$ In their metaanalysis, Zhan et al noted a much higher cement leakage rate of $54.7 \%$ (vertebroplasty) and $18.4 \%$ (kyphoplasty) respectively. For our study we considered cement $\leq 3 \mathrm{~mL}$ to be a relatively low volume and anything greater to be high volume. It was interesting that pulmonary vessel cement uptake occurred exclusively in high volume while intradiscal extravasation occurred exclusively in low volume. Both complications did occur predominantly in patients with kyphoplasty, which was unexpected. Intraoperative venous uptake of cement can go undetected, which can lead to injecting higher volumes of cement. In contrast, intradiscal extravasations are more easily detected intraoperatively, which leads to termination of the procedure at a lower volume of cement.

This study as several limitations. We did not analyze or account for a floor value of cement but arbitrarily determined a cut-off point of $3 \mathrm{ml}$. It is likely that a lower volume of cement may have provided a therapeutic benefit as well. Molloy et al showed that $2 \mathrm{cc}$ of polymethylmethacrylate improved strength and stiffness in thoracic compression fractures by $69 \%$ and $80 \%$ respectively. ${ }^{9}$ Thus based on this study, achieving $100 \%$ restoration is likely not needed to receive full clinical benefit. Nonetheless, in our study we did not use volumes lower than $1 \mathrm{ml}$ due to impracticality. The study does not include follow up beyond four weeks. We also included patients with a mix of benign and malignant diagnoses, which could have an effect on the measured outcomes. Finally, due to the small number of patients, we were not able to perform separate analysis for patients that underwent vertebroplasty and kyphoplasty.

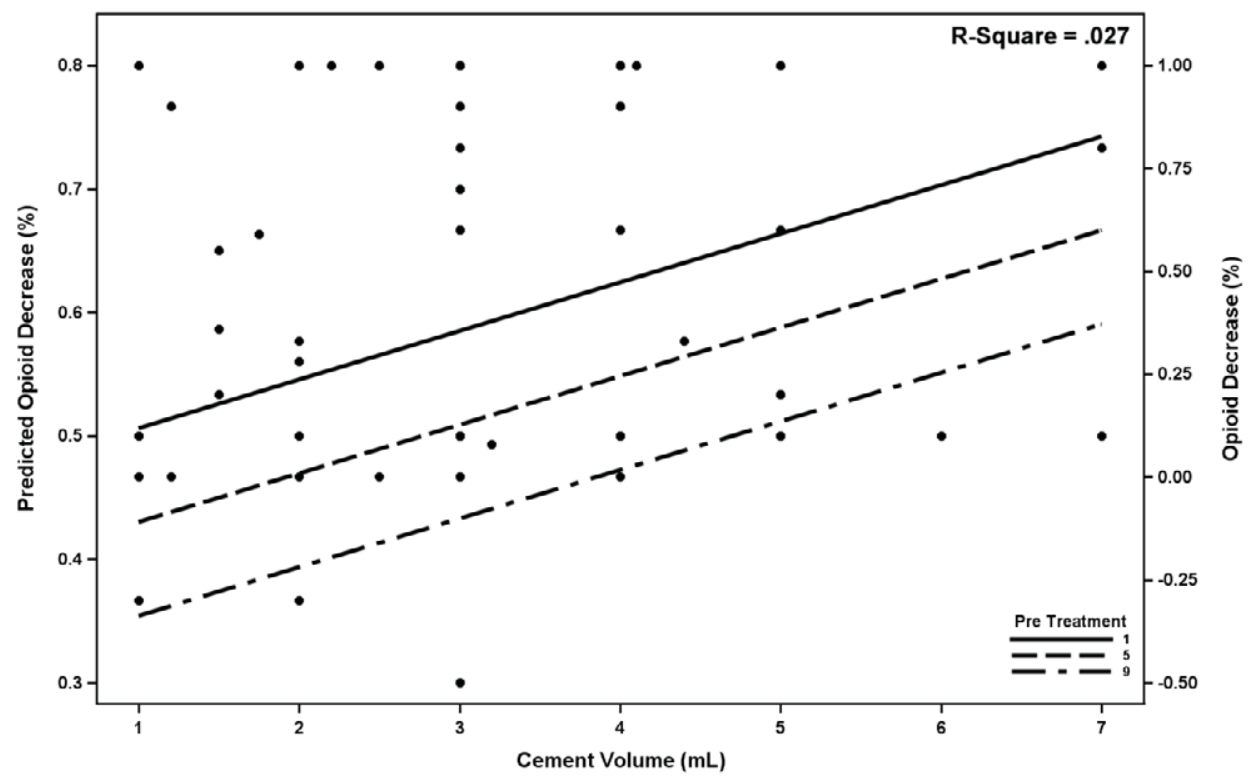

Figure 4. Opioid decrease by cement volume and pre-treatment score. Scatter plot displaying linear regression analysis with two independent variables (adjusted for pre-NPS covariate and relationship of opioid decrease with cement volume). Three regression lines are drawn with various pre-treatment NPS scores $(1,5,9)$ that failed to show significance $(p=.299$ and $R 2=0.027)$. The left axis refers to the pre-treatment lines and the right axis refers to the plotted points. Positive opioid decrease implies a reduction, while negative infers opioid increase. Abbreviations: NPS=Numeric Pain Score. 
In summary, the results of our study demonstrated a beneficial effect of vertebroplasty and kyphoplasty with a reduction in NPS and opioid consumption. Further studies with a larger number of patients are needed to validate our findings.

https://doi.org/10.32873/unmc.dc.gmerj.2.1.004

\section{References}

1 Diamond TH, Champion B, Clark WA. Management of acute osteoporotic vertebral fractures: a nonrandomized trial comparing percutaneous vertebroplasty with conservative therapy. The American Journal of Medicine. Mar 2003;114(4):257 265

2 Voggenreiter G. Balloon kyphoplasty is effective in deformity correction of osteoporotic vertebral compression fractures. Spine. Dec 15 2005;30(24):2806-2812.

3 Papaioannou A, Adachi JD, Parkinson W, Stephenson G, Bedard M. Lengthy hospitalization associated with vertebral fractures despite control for comorbid conditions. Osteoporosis International: A Journal Established as Result of Cooperation Between the European Foundation for Osteoporosis and the National Osteoporosis Foundation of the USA. 2001;12(10):870-874

4 Chen AT, Cohen DB, Skolasky RL. Impact of nonoperative treatment, vertebroplasty, and kyphoplasty on survival and morbidity after vertebral compression fracture in the medicare population. The Journal of Bone and Joint Surgery. American volume. Oct 02 2013;95(19):1729-1736.

5 Burge R, Dawson-Hughes B, Solomon DH, Wong JB King A, Tosteson A. Incidence and economic burden of osteoporosis-related fractures in the United States, 2005-2025. Journal of Bone and Mineral Research: The Official Journal of the American Society for Bone and Mineral Research. Mar 2007;22(3):465-475.

6 Silverman SL, Minshall ME, Shen W, Harper KD, Xie S, Health-Related Quality of Life Subgroup of the Multiple Outcomes of Raloxifene Evaluation $\mathrm{S}$. The relationship of health-related quality of life to prevalent and incident vertebral fractures in postmenopausal women with osteoporosis: results from the Multiple Outcomes of Raloxifene Evaluation Study. Arthritis and Rheumatism. Noy 2001;44(11):2611-2619.

7 Borgstrom F, Zethraeus N, Johnell O, et al. Costs and quality of life associated with osteoporosis-related fractures in Sweden. Osteoporosis International: A Journal Established as Result of Cooperation Between the European Foundation for Osteoporosis and the National Osteoporosis Foundation of the USA 2006;17(5):637-650

Table 1.

The total number of complications by type of complication. Each type of complication is then further separated based on type of procedure and cement volume injected.

\begin{tabular}{lcccccc} 
Type Of Complication & Total \# & $\begin{array}{c}\text { Complication } \\
\%\end{array}$ & $\begin{array}{c}\text { Kyphoplasty } \\
\#\end{array}$ & $\begin{array}{c}\text { Vertebroplasty } \\
\#\end{array}$ & $\begin{array}{c}\text { Cement } \\
\mathbf{3} \mathbf{m L}\end{array}$ & $\begin{array}{c}\text { Cement } \\
\mathbf{3} \mathbf{m l}\end{array}$ \\
\hline Intradiscal Extravasation & 4 & $4.5 \%$ & 3 & 1 & 4 & 0 \\
\hline Pulmonary Embolism & 3 & $3.4 \%$ & 3 & 0 & 0 & 3 \\
\hline $\begin{array}{l}\text { Uncomplicated Venous } \\
\text { Extravasation }\end{array}$ & 2 & $2.3 \%$ & 1 & 1 & 1 & 1 \\
\hline
\end{tabular}

8 Belkoff SM, Mathis JM, Jasper LE, Deramond H. The biomechanics of vertebroplasty. The effect of cement volume on mechanical behavior. Spine. Jul 15 2001;26(14):1537-1541.

9 Molloy S, Mathis JM, Belkoff SM. The effect of vertebral body percentage fill on mechanical behavior during percutaneous vertebroplasty. Spine. Jul 15 2003;28(14):1549-1554.

10 Molloy S, Riley LH, 3rd, Belkoff SM. Effect of cement volume and placement on mechanicalproperty restoration resulting from vertebroplasty. AJNR. American Journal of Neuroradiology. Feb 2005;26(2):401-404.

11 Luo J, Daines L, Charalambous A, Adams MA, Annesley-Williams DJ, Dolan P. Vertebroplasty: only small cement volumes are required to normalize stres distributions on the vertebral bodies. Spine. Dec 15 2009;34(26):2865-2873.

12 Liebschner MA, Rosenberg WS, Keaveny TM. Effects of bone cement volume and distribution on vertebral stiffness after vertebroplasty. Spine. Jul 15 2001;26(14):1547-1554.

13 Kim JM, Shin DA, Byun DH, Kim HS, Kim S, Kim HI. Effect of bone cement volume and stiffness on occurrences of adjacent vertebral fractures after vertebroplasty. Journal of Korean Neurosurgical Society. Nov 2012;52(5):435-440.

14 Zhan Y, Jiang J, Liao H, Tan H, Yang K. Risk factors for cement leakage after vertebroplasty or kyphoplasty: a meta-analysis of published evidence. World Neurosurgery. Feb 092017

15 Ryu KS, Park CK, Kim MC, Kang JK. Dosedependent epidural leakage of polymethylmethacrylate after percutaneous vertebroplasty in patients with osteoporotic vertebral compression fractures. Journal of Neurosurgery. Jan 2002;96(1 Suppl):56-61.

16 Kaufmann TJ, Trout AT, Kallmes DF. The effects of cement volume on clinical outcomes of percutaneous vertebroplasty. AJNR. American journal of Neuroradiology. Oct 2006;27(9):1933-1937.

17 He X, Li H, Meng Y, et al. Percutaneous Kyphoplasty Evaluated by Cement Volume and Distribution: An Analysis of Clinical Data. Pain Physician. Sep-Oct 2016;19(7):495-506.

\section{Acknowledgements}

We would like to acknowledge the following individuals for their contribution to this study:

1 Robin High, MBA,MA

Statistical Coordinator, Department of Biostatistics

University of Nebraska Medical Center, Omaha, NE

Contribution: Robin helped with the statistical analysis and graph development.

2 Julia Hoffman, RN, BSN

Research Nurse Coordinator, Department of Anesthesiology

University of Nebraska Medical Center, Omaha, NE

Contribution: Julia helped with the entire Institutional Review Board approval and maintenance process.

18 Hodler J, Peck D, Gilula LA. Midterm outcome after vertebroplasty: predictive value of technical and patient- related factors. Radiology. Jun 2003;227(3):662-668

19 Nieuwenhuijse MJ, Bollen L, van Erkel AR, Dijkstra PD. Optimal intravertebral cement volume in percutaneous vertebroplasty for painful osteoporotic vertebral compression fractures. Spine. Sep 15 2012;37(20):1747-1755.

20 Buchbinder R, Osborne RH, Ebeling PR, et al. A randomized trial of vertebroplasty for painful osteoporotic vertebral fractures. The New England Journal of Medicine. Aug 06 2009;361(6):557-568.

21 Kallmes DF, Comstock BA, Heagerty PJ, et al. A randomized trial of vertebroplasty for osteoporotic spinal fractures. The New England Journal of Medicine. Aug 06 2009;361(6):569-579.

22 Boonen S, Van Meirhaeghe J, Bastian L, et al. Balloon kyphoplasty for the treatment of acute vertebral compression fractures: 2-year results from a randomized trial. Journal of Bone and Mineral Research: The Official Journal of the American Society for Bone and Mineral Research. Jul 2011;26(7):1627-1637.

23 Wardlaw D, Cummings SR, Van Meirhaeghe J, et al Efficacy and safety of balloon kyphoplasty compared with non-surgical care for vertebral compression fracture (FREE): a randomised controlled trial. Lancet Mar 21 2009;373(9668):1016-1024.

24 Tolba R, Bolash RB, Shroll J, et al. Kyphoplasty increases vertebral height, decreases both pain score and opiate requirements while improving functional status. Pain Practice: The Official Journal of World Institute of Pain. Mar 2014;14(3):E91-97. 